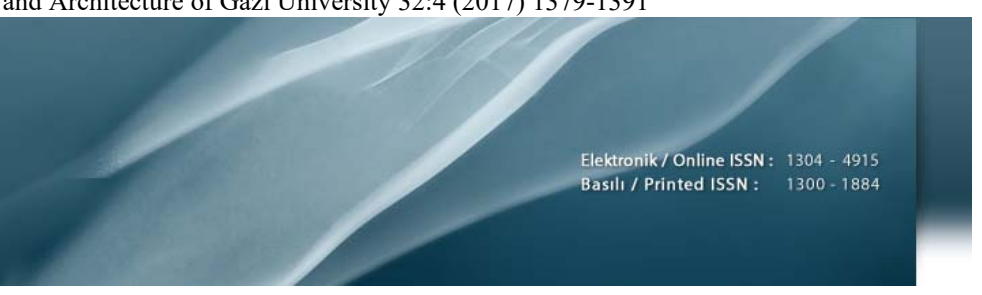

\title{
Çok fonksiyonlu form değiştirebilir köprü tasarımı için iki serbestlikli strüktürel mekanizma önerisi
}

Şebnem Gür*iD, Müjde Yar(D), Koray Korkmaz (D)

İzmir Yüksek Teknoloji Enstitüsü, Mimarlık Fakültesi, Mimarlık Bölümü, İzmir 35430, Türkiye

Ö N E Ç I K A N L A R

- Hareketli köprü tasarımı

- Konkav formdan konveks forma dönüşebilen çok devreli mekanizma

- $\quad$ Pozisyon analizi

Makale Bilgileri

Geliş: 22.09.2016

Kabul: 04.10.2017

DOI:

10.17341/gazimmfd.369866

Anahtar Kelimeler:

Hareketli köprü, antiparalelkenar mekanizma, pozisyon analizi

\section{ÖZET}

Hareketli köprüler ilk zamanlar korunma ihtiyacı ile tasarlanmıștır. Modern zamanlarda ise ulaşımı kolaylaştırmak için geliştirilmeye devam edilmektedir. Sabit köprülerin aksine farklı kullanım senaryolarını desteklemeleri sebebiyle tercih edilmektedirler. Bu yazıda mevcut hareketli köprüler kinematik özellikleri açısından tanıtılmış, hangi kullanım seneryolarını destekledikleri ve eksik kaldıkları yönler açıklanmıştır. Daha sonra güncel bir örnek olan Rolling Bridge'de kullanılmış strüktürel mekanizmanın tasarım prensiplerden yararlanarak, tüm kullanım senaryolarını destekleyen form değiştirebilen köprü için çok devreli ve iki serbestlikli yeni bir strüktürel mekanizma önerilmiştir. Son olarak mekanizmanın pozisyon analizi yapılarak Microsoft Excel ${ }^{\circledR}$ ortamında gerçekleştirilen grafik sunulmuştur.

\section{A novel two degrees-of-freedom structural mechanism proposal for multi-functional transformable bridge}

\section{H I G H L I G H T S}

\section{- Moveable bridge design}

- Antiparallelogram mechanism transforming from concave to convex

- Position analysis

\section{Article Info}

Received: 22.09 .2016

Accepted: 04.10.2017

DOI:

10.17341/gazimmfd.369866

Keywords:

Moveable bridge, antiparallelogram mechanism,

position analysis

\section{ABSTRACT}

At first moveable bridges are built with the need of protection. Also they are developed to ease transportation in modern times. They are in favor compared to stable bridges due to their adaptive capabilities for various situations. In this article existing moveable bridges are introduced in terms of their kinematic properties and their abilities to respond different transportation needs are examined. Later on, making use of the structural mechanism design principles of a contemporary example, the Rolling Bridge, a novel two degrees-offreedom multi-loop structural mechanism that can support all types of usage scenarios is proposed for a transformable bridge. Lastly a position analysis of the mechanism is done and a graphic is presented in Microsoft Excel ${ }^{\mathbb{}}$.

\footnotetext{
*Sorumlu Yazar/Corresponding Author: sebnemgur@iyte.edu.tr / Tel: +90 2327507032
} 


\section{GÍRIŞ (INTRODUCTION)}

Tarihte hareketli köprü tasarımları ilk olarak kalelerin ve şehirlerin düşman saldırılarından korunmasını güçlendirmek için ortaya çıkmıştır. Bu köprüler ile ilgili ilk el kitabı da 1882 gibi erken tarihte Fränkel [1] tarafından kaleme alınmıştır. 1970'lere kadar Amerika Birleşik Devletleri'nde inşa edilmiş köprülerin tarihçesi bolca örnek ile birlikte Hardesty vd. [2, 3] ve Wengenroth ile Howard [4] yayınlarında bulunabilir. Erken döneme ait bazı hareketli köprüler ile ilgili olarak Waddell [5], Greene ve McKeen [6], Quade [7] incelenebilecek diğer yayınlardır. Tüm bu yayınlarda hareketli köprüler 13 tür altında incelenmiş ve yayınlandıkları dönem itibariyle en yaygın üç tür olan, baskül kullanımı, döndürme ve yükseltme geleneksel yöntemler olarak adlandırılmıştır. Bu tabir Abrahams [8] ve daha yakın tarihli olan Koglin [9] yayınında da tekrarlanmıştır. Modern zamanlarda da savunmadan ziyade, deniz ve nehir araçlarının da geçişi için bu üç geleneksel yöntem kullanılmaktadır. Baskül köprüler (Şekil 1a) karş1 ağırlıklar yardımı ile bir yakadaki yatay mafsal ekseninde dönerek açılırken, döner köprüler (Şekil 1b) ise kimi zaman bir yakada kimi zaman ise açıklığın ortasında yer alan düşey bir mafsal etrafinda döndürülerek yolu açar. Yükselen köprüler (Şekil 1c) de yine karşı ağırlıklar yardımıyla köprü güvertesini yükselterek üstünden geçen trafiği kapatıp altından geçecek trafiğe izin verir. $\mathrm{Bu}$ geleneksel yöntemlerde köprü güvertesi yekpare katı bir yapıdır; formu değişmez veya kompakt olarak kapanamaz. Çoğu zaman katı olmayan kablo elemanlar da strüktürün parçasıdır.

Son yıllarda ise yeni yöntemler geliştirilmektedir. Kiel, Almanya'da yer alan Hörn yaya köprüsü [10] üç parçadan oluşmakta ve motorlar ile çekilen kablolar yardımıyla katlanarak tek yakada toplanmaktadır. Deniz ulaşımı için köprü üstündeki trafik durmaktadır. Duisburg'da yer alan iç körfez yaya köprüsü [11] ise güverteyi taşımak için iki kolon arasında gerilmiş kablo sisteminden faydalanmış ve kolonları karaya doğru döndürülerek köprü güvertesinin yükselerek kemer formunu almasını sağlamıştır. Yapı hem üstten hem de alttan trafiği sağlamaktadır ancak yüksek deniz taşıtlarının geçişi için köprünün toplanması mümkün değildir. Lederman vd. [12] tarafından geliştirilen açılabilir köprü ise açılı blok ünitelerin mafsallar ile birleştirilerek yığma kemer yapısını andıran formda geçilen açıklığın üzerinde konumlanmasını amaçlamaktadır. Bunu sağlamak için serbest olan uçta silindir bir makara güverteyi oluşturan bloklardan da geçen kablolar ile başlangıç noktasına bağlanmıştır. Üstte yer alan bu kablolar gevşetilerek sistem açılırken alttaki kablo gerilerek formun stabilitesi sağlanır. $\mathrm{Bu}$ köprü sisteminde hem üst hem alt trafik desteklenmektedir ancak açıldığında kemer formunda olan yap1 yayalara düz bir köprü zemini sunamamaktadır. Kablolardan faydalanmadan sadece katı elemanlar ile oluşturulmuş hareketli köprüler de bulunmaktadır. Bunlara bir örnek Hiroshima Üniversitesi'nde geliștirilen, makas mekanizmasının kullanıldığı öteleme hareketi yapan acil durum köprüsüdür [13]. Bu köprü tek hareket kaynağı ile kurulabilmekte fakat yaya ve deniz ulaşımına aynı anda izin verememektedir. Küçülerek toplanabilmesi ve taşınabilir oluşu ise önemli bir avantajıdır. Katı elemanlardan oluşan ve modern hareketli köprü olan bir diğer örnek ise Paddington, İngiltere'de yer alan Rolling Bridge'dir [14]. İngiliz tasarımc1 Thomas Heatherwick tarafindan tasarlanıp 2005 y1lında inşa edilen Rolling Bridge, Grand Union kanalı üzerinde yaya ulaşımını sağlamaktadır. Köprü birleştirdiği iki yakadan birine doğru pistonlar yardımı ile kıvrılarak toplanmaktadır. Kablo yerine pistonların kullanılması, köprü formunun hareketin her aşamasında kontrol edilebilir olmasını sağlamaktadır. Köprünün her iki korkuluğundaki hareketi sağlayan yedişer piston eş zamanlı çalışır ve köprü sekizgen oluşturarak bir yakada toplanır [15]. Heatherwick tasarımının kapandığında sekizgen şeklinde toplanmasını ve açıldığında yaya köprüsü işlevini yerine getirebilecek düz bir form almasını tercih etmiştir. Kapalı formunda estetik bir görünüşe sahip olmasına rağmen, bu köprü kemer formunu alıp yaya geçişi ve deniz taşıtı geçişine eş zamanlı olarak izin verememektedir [16]. Ayrıca zamanlamada kayma olması durumunda mekanizmanın sıkışması da mümkündür.

Rolling Bridge'deki gibi çok sayıda piston yerine tek bir piston ile de çok devreli strüktürel mekanizmalar tasarlanabilir ve köprü işlevli kullanılabilir. Sadece katı elemanlar kullanılarak tek bir dış kuvvet ile hareket edebilir çok devreli strüktürel mekanizma tasarımı üzerine oldukça fazla çalışma vardır. Maden vd. [17] yaptıkları çalışmada çok devreli makas mekanizmaların geometrik ve strüktürel özelliklerini incelemişlerdir. Cai vd. [18] ise yine makas mekanizmadan oluşan hareketli çatı strüktürlerini incelemişlerdir. Bir diğer örnek ise Bouleau ve Guscetti'nin [19] tasarladığı makas mekanizmalı hareketli bir köprüdür. Makas mekanizmalar kutupsal makas (Şekil 2a) ve açılı makas (Şekil 2b) birimlerden oluşmaktadır. Bu iki birim makasın mafsal noktalarından çizilen doğrular bir noktada kesişir ve aralarındaki açıya birim açısı $(\beta)$ denir. Birim açı kutupsal makas kapanıp açılırken değişir, açılı makas kapanıp açılırken değişmez. Bu sebeple Hoberman dairesel alanları bir merkeze doğru toplanıp tekrar açılabilir bir

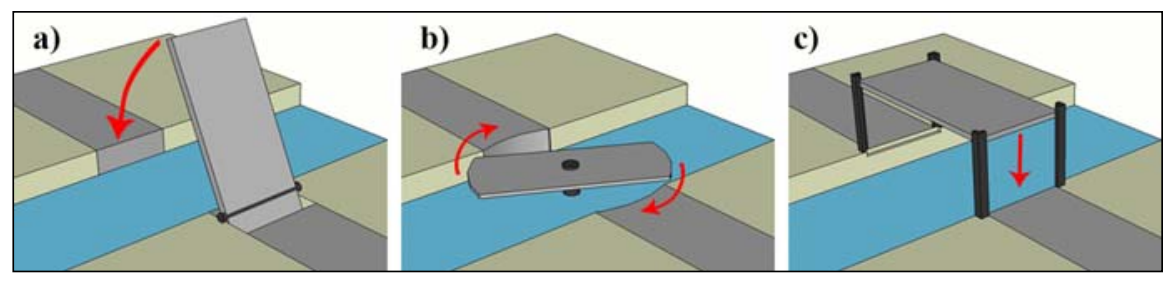

Şekil 1. a) Baskül köprü b) Döner köprü c) Yükselen köprü ( a) Bascule bridge b) Swing bridge c) Lift bridge) 
strüktürel mekanizma ile örtmek için açılı birim mekanizmayı kullanmıştır [20]. Kemer formunda bir strüktürel mekanizma içinse her iki birim makas da kullanılabilir. $\mathrm{Bu}$ iki makas birimlerin kullanıldı $\breve{g}_{1}$ mekanizmalar bir merkeze doğru toplanıp tekrar açılır (Şekil 3). Açılı makas sistemini kullanan bir köprü çalışması da Bouleau ve Guscetti tarafindan tasarlanan Cenevre'de yer alan "Jet d'Eau" yaya köprüsüdür [19]. Düz formdan kemer formuna geçebilen mekanizması ile bu köprü alçak deniz taşıtları ve yayaların eş zamanlı geçişine olanak vermekte ancak yüksek deniz taşıtlarının geçişi için açılamamaktadır. $\mathrm{Bu}$ gibi köprü veya daha başka hareketli yapıların mekanizmasının tasarımı ve analizi için çeşitli bilgisayar programlarının kullanılması da gerekmiştir [21].

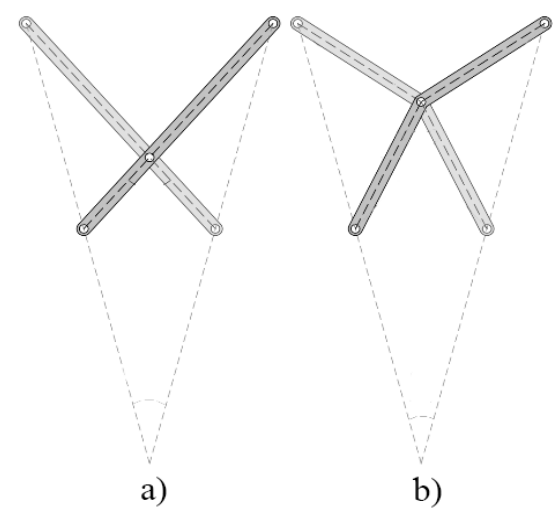

Şekil 2. a) Kutupsal makas b) Açılı Makas (a) Polar scissor b) Angular scissor)

Yapılan literatür araştırmasında yaya veya deniz ulaşımından kaynaklanan gereksinime göre, eğriliği değişerek bazen düz, bazen kemer formu alan ve de bir yakada toplanabilen bir köprü tasarımına rastlanmamıştır. Robotik alanında eğriliği değişerek kemer formdan düz forma dönüşebilen mekanizmaların robot parmağı (finger mechanism) olarak önerildiği çalışmalar vardır. Katı çubuk elemanlardan oluşturulmuş çok devreli bir mekanizma Jang vd. tarafından tasarlanmıştır [22]. Bir diğer örnek ise Sun vd. tarafından tasarlanan çubuk elemanlarla birlikte dişli mekanizmasının ve kayış-kasnak mekanizmasının da kullanıldığı daha karmaşık bir mekanizmadır [23]. Bu mekanizmalar da insan parmağını taklit etmek için eğri formdan düz forma dönüşebilmekte ama eğrilik içbükeyden dışbükeye dönüşememektedir. $\mathrm{Bu}$ makalede öncelikle içbükey formdan dişbükey forma dönüşebilen tek serbestlik dereceli katı çubuklardan oluşan çok devreli bir mekanizma tasarlanmış ve Microsoft Excel ${ }^{\circledR}$ ile mekanizmanın çubuk boyları kesinleştirilmiştir. Daha sonra bir piston daha eklenerek iki serbestlik dereceli düz ve kemer formlarını alabilen hatta eğrilik merkezi yer değiştirerek bir yakada toplanabilen mekanizmanın bir yaya köprüsü olarak kullanılabileceği önerilmiştir. Önerilen iki serbestlik dereceli mekanizmanın pozisyon analizi de Microsoft Excel ${ }^{\circledR}$ ortamında yapılmıştır. Bu Microsoft Excel $^{\circledR}$ dosyası üzerinden her bir çubuk boyu değiştirilerek veya pistonlar uzatılıp k1saltılarak mekanizmanın her durumda kinematik diyagramı tekrar tekrar çizdirilebilmektedir.

\section{HEATHERWICK KÖPRÜSÜNÜN KİNEMATİK ANALIZI (KINEMATIC ANALYSIS OF HEATHERWICK BRIDGE)}

Heatherwick'in [24] tasarladığ 12 metrelik bir açıklığ geçen Rolling Bridge'i kinematik olarak incelediğimizde her bir korkuluk kolunun 36 uzuv, 42 döner ve 7 kayar olmak üzere 49 mafsaldan oluştuğunu görüyoruz (Şekil 4). Mekanizmaların serbestlik derecelerini inceleyen Grübler'in denklemine (Eş. 1) göre:

$M=\lambda(n-1)-\sum_{i=1}^{5}(\lambda-i) j_{i}$

M serbestlik derecesi, $n$ toplam çubuk sayısı, $\mathrm{j}_{\mathrm{i}} \mathrm{i}$ sayıda serbestlik dereceli mafsal sayısı, $\lambda$ uzay serbestlik derecesidir. Düzlemsel mekanizmalarda uzay serbestlik derecesi üçtür. $\mathrm{Bu}$ koşul ile Grübler'in denklemini yorumlayan Kutzbach'ın [25] denklem varyasyonu (Eş. 2) ise şu şekildedir:

$M=3(n-1)-2 j_{1}-j_{2}$

$\mathrm{Bu}$ denklemde $\mathrm{j}_{1}$ tek serbestlik dereceli mafsal sayısı, $\mathrm{j}_{2}$ iki serbestlik dereceli mafsal sayısıdır. Heatherwick'in köprüsü

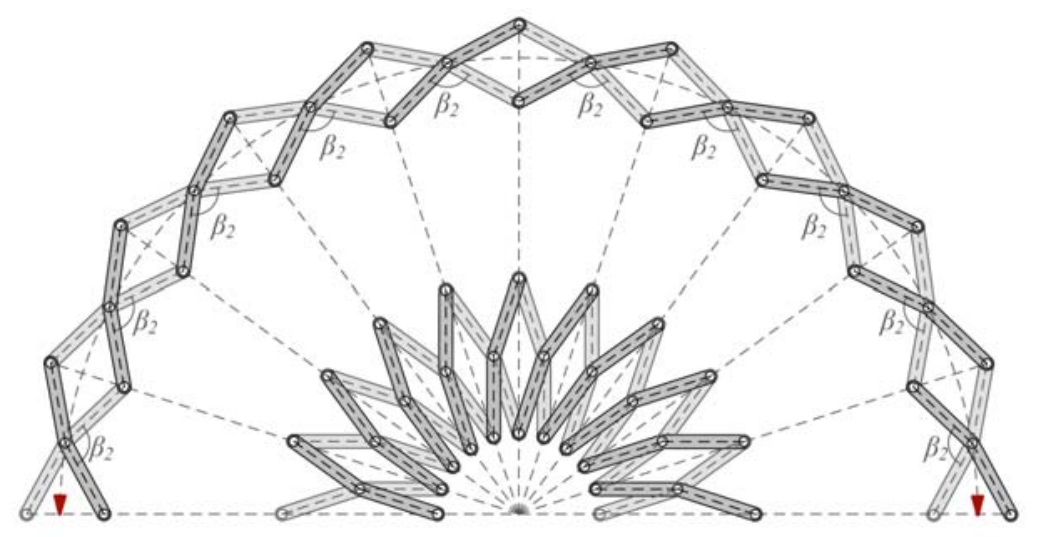

Şekil 3. Açılı birim makas kullanılarak üretilmiş merkeze doğru toplanabilen kemer formunda mekanizma (Mechanism in arch form made out of angulated scissor units which can contract towards the center) 
bu denkleme (Eş. 3) göre yedi serbestlikli bir strüktürel mekanizmadir.

$\mathrm{M}=3(36-1)-2 \times 49-0 \rightarrow \mathrm{M}=7^{\prime}$ dir.

Ayrıca Rasim Alizade'nin [26] devre sayılarını kullandı̆̆ı formülü (Eş. 4) ile de sağlamasını yapabiliriz. Freudenstein ve Alizade'nin denklemi şu şekildedir:

$\mathrm{M}=\sum_{\mathrm{i}=1}^{\mathrm{j}} \mathrm{fi}-\sum_{\mathrm{K}=1}^{\mathrm{L}} \lambda \mathrm{k}+\mathrm{q}-\mathrm{j}_{\mathrm{p}}$

M serbestlik derecesi, fi i-sayıda kinematik çiftin serbestliği toplamı, $\lambda \mathrm{k}$ k-sayıda devrenin uzaysal küme ve altkümeleri, q fuzuli çubuk sayısı, jp pasif mafsal sayısı, L bağımsız devre sayısıdır. Bağımsız devre sayısı Euler'in denklemi (Eş. 5) ile hesaplanabilmektedir. Bu denkleme göre;

$\mathrm{m}+\mathrm{L}-\mathrm{j}=1$

m toplam çubuk sayısı, L bağımsız devre sayısı, j mafsal sayısıdır. Köprü için uygularsak (Eş. 6):

$36+\mathrm{L}-49=1 \rightarrow \mathrm{L}=14$ ’tür.

Freudenstein ve Alizade denklemine (Es 7) yerleştirdiğimizde;
$M=(49 \times 1)-(14 \times 3)+0-0 \rightarrow M=7^{\prime}$ dir.

Yapının tasarımında dört uzuvlu devreler birleştirilerek çoğaltılmıştır. Köprünün devrelerinin ekleniş şeklini incelersek iki farklı yöntem görülmektedir. Bunların ilki piston mekanizmasını ortak kullanan iki devre birleşimidir. Burada pistonu oluşturan iki uzuv ortak kullanılmış, toplam altı uzuv yedi mafsal ile birleştirilmiştir. Eğer yine formüle (Eş. 8) koyarsak, iki devrenin birleşerek yine tek serbestlik dereceli bir yapı oluşturduğu anlaş1lır (Şekil 5a).

$\mathrm{M}=3(6-1)-2 \times 7-0 \rightarrow \mathrm{M}=1$ 'dir.

İkinci birleşim yöntemi ise, dört köşesinde mafsalları olan dört kinematik elemanlı uzvun $\mathrm{L}_{2}$ ve $\mathrm{L}_{3}$ devreleri için ortak eleman olarak kullanıldığı durumdur. $\mathrm{Bu}$ durumda toplam yedi eleman sekiz mafsal ile birleştirilmiştir (Şekil 5b). Formül ile incelediğimizde de görüyoruz ki bu mekanizma iki serbestlikli bir yapıdır. İki devrenin tek bir ortak uzuvla birleştirilmesi serbestlik derecesini bir artırmıştır. Köprünün tamamında yedi tane birinci tip, yedi tane de ikinci tip devre birleşimi bulunduğundan toplam serbestlik derecesi de yedi olmaktadır. Devrelerin birleşimleri bu durumdan da anlaşılacağı gibi mekanizmanın serbestliğini artırmakta veya sabit tutmaktadır (Eş. 9).

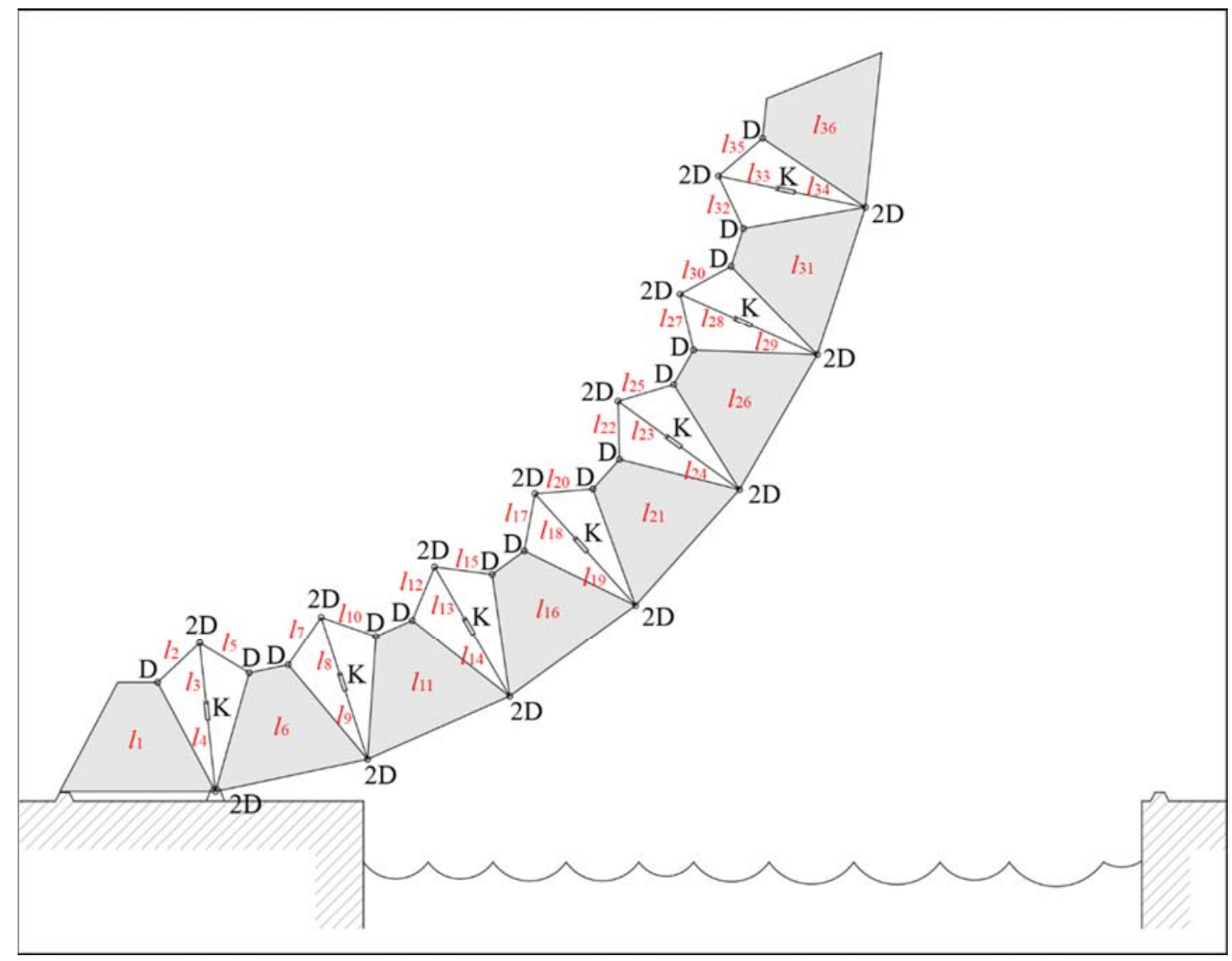

Şekil 4. Rolling Bridge kinematik şeması (Rolling Bridge kinematic diagram) 


\section{3. İÇBÜKEY VE DIŞBÜKEY BICÇIMLERE DÖNÜŞEBILEN MEKANIZMANIN TASARIMI (DESIGN OF A MECHANISM TRANSFORMABLE BETWEEN CONCAVE AND CONVEX FORMS)}

Antiparalelkenar kapalı devre oluşturan bir diğer tanımlı mekanizmadır. Antiparalelkenar mekanizması (Şekil 6c), paralelkenar mekanizması (Şekil 6a) gibi, dört çubuktan oluşur; devre sayısı ve serbestlik derecesi birdir. Paralelkenar mekanizmada bir çubuk döndürüldüğünde çubuklar arasındaki paralel ilişki bozulmaz. Şekil 6 b'de $l 2$ çubuğu döndürüldüğünde $l 3$ çubuğu $l 1$ sabit çubuğuna, $l 2$ ve 14 çubukları da birbirlerine paralel kalmaktadır. Antiparalelkenar mekanizmada ise bir çubuğun rotasyonu çubuklar arasındaki ilişkileri değiştirir. Şekil 6d'de görüldüğü gibi $l 2$ çubuğunu döndürdüğümüzde $l 3$ çubuğunun paralelliği bozularak açısı değişmektedir. $l 2$ çubuğunun dönme yönüne göre $l 3$ çubuğu iki farklı yöne de dönebilmektedir. $\mathrm{Bu}$ durum antiparalelkenar devrelerin birleştirilmesi ile elde edilecek bir mekanizmanın her iki tarafa doğru hareket edebilirliği üzerine ipucu vermektedir. Tasarlanacak strüktürel mekanizmada serbestlik derecesini bir olarak korumak için izlenebilecek yöntem Şekil 5a da olduğu gibi, iki çubuğun ortak eleman olarak kullanılmasıdır. Bu düzende eklenen her ünite ile iki uzuv ve üç mafsal mekanizmaya dahil olur. Elemanların ortak kullanılabilmesi için iki devreden birer uzuv birleşerek, üç kinematik elemanlı (ternary) uzuvlar oluşturur (Şekil 7a). Üçüncü bir devreyi eklediğimizde ise, yine komșu iki devrenin birer uzvu birleşir ancak zaten üç kinematik elemanlı hale gelmiş olan uzuv bu sefer dört kinematik elemanlı (quaternary) olacaktır (Şekil 7b, c). Devre sayısı arttırıldıkça, devre sayısının iki eksiği kadar dört kinematik elemanlı uzuv ve iki adet üç kinematik elemanlı uzuv elde edilir.

Üç devreli bir mekanizmada, Grübler denklemine (Eş. 10) göre;

$\mathrm{M}=3(8-1)-2 \times 10-0 \rightarrow \mathrm{M}=1$ 'dir.

Euler denklemine göre devre sayısı (Eş. 11);

8+L-10=1 $\rightarrow$ L=3’tür.

Freudenstein ve Alizade'nin denklemine (Eş. 12) göre;

$\mathrm{M}=(10 \times 1)-(3 \times 3)+0-0 \rightarrow M=1$ 'dir.

$\mathrm{Bu}$ yöntem ile oluşturulmuş dört antiparalelkenar devreden oluşan bir sistem ön çalışmalar sırasında tasarlanarak çalışır bir modeli tarafımızdan üretilmiştir (Şekil 8).

Aynı şekilde, zinciri uzatıp altı adet antiparalelkenar devre birleştirilerek yedi devreli bir mekanizmayı aşağıdaki gibi oluşturabiliriz. Bu haliyle strüktürel mekanizma toplanıp açılma hareketini tek hareket kaynağı ile gerçekleştirebilmektedir. Yeni mekanizma 16 uzuv, 21 döner ve 1 kayar mafsaldan oluşmaktadır (Şekil 9).

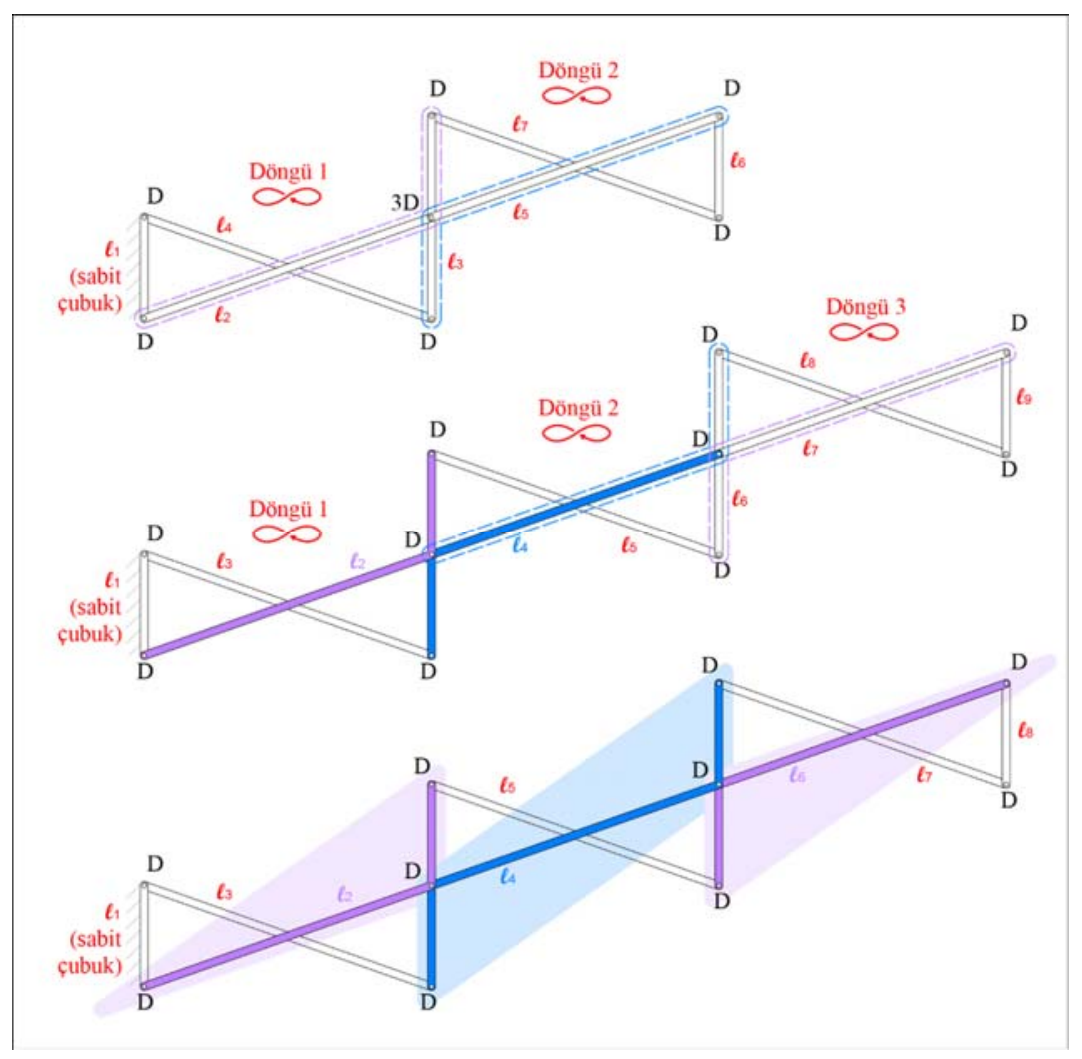

Şekil 7. Antiparalelkenar ünitelerin iki ortak eleman ile çoğaltılması (Assembly of antiparallelogram mechanisms with two common links) 


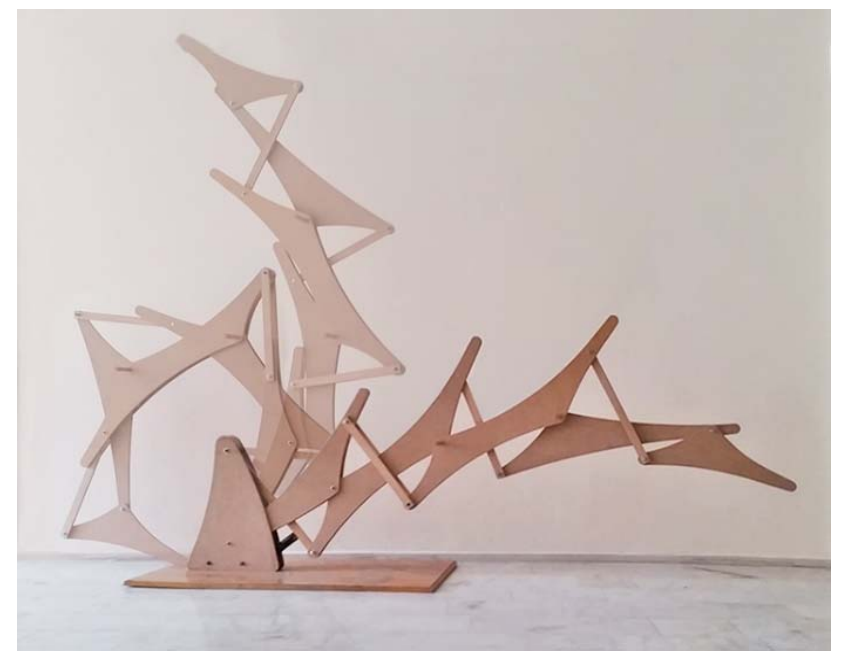

Şekil 8. Dört antiparalelkenar devreden oluşan mekanizma (A mechanism consists of four antiparallel loops)

Yine formülleri uygularsak serbestlik derecesinin bir olduğunu onaylayabiliriz. Grübler denklemine göre (Eş. 13);

$\mathrm{M}=3(16-1)-2 \times 22-0 \rightarrow \mathrm{M}=1^{\prime}$ dir.

Euler denklemine göre (Eş. 14) devre sayısı;

$16+\mathrm{L}-22=1 \rightarrow \mathrm{L}=7$ 'dir.

Freudenstein ve Alizade'nin denklemine göre (Eş. 15);

$\mathrm{M}=(22 \times 1)-(7 \times 3)+0-0 \rightarrow \mathrm{M}=1$ 'dir.

Strüktürel mekanizmanın farklı formlar alabilmesi için hareketini sağlayan pistonun yanı sıra, ikinci bir piston ile hareket kabiliyeti daha da artırılabilir. İkinci piston ile mekanizma 19 uzuv, 24 döner ve 2 kayar mafsaldan oluşur. (Şekil 10).

İki piston ile hareket ettirilebilen bu strüktürel mekanizmanın serbestlik derecesi de iki olmalıdır. Grübler denklemine göre (Eş. 16);

$\mathrm{M}=3(19-1)-2 \times 26-0 \rightarrow \mathrm{M}=2^{\prime}$ 'dir.

Euler denklemine göre devre sayısı (Eş. 17);

19+L-26=1 $\rightarrow$ L=8' dir.

Freudenstein ve Alizade'nin denklemine göre (Eş. 18);

$M=(26 \times 1)-(8 \times 3)+0-0 \rightarrow M=2^{\prime}$ dir.

Mekanizmaya ikinci bir hareket kaynağının eklenmesi ile bir yakada toplanabilmesinin yanı sira tercihe göre kemer formuna ek olarak düz formdayken de indirilip yaya geçişine imkân sağlayabilir (Şekil 11).

\section{POZİSYON ANALİİ (POSITION ANALYSIS)}

Kenar uzunlukları ve iç açıları önceden belirlenmiş uzuvlar dışında, değişken olarak sadece iki pistonun boylarının belirlenmesi ile Erez Söylemez'in [27] geliştirdiği pozisyon analizi metodu ile tüm sistem elemanlarının konumu trigonometrik hesap ile bulunabilir. (Şekil 12).

Yaptığımız çalışmada sistemi kinematik olarak incelerken A noktasını 0,0 koordinatlarında belirledik. Buradan yola çıkarak, önce X noktasının koordinatları şu şekilde belirlenmelidir (Eş. 19);

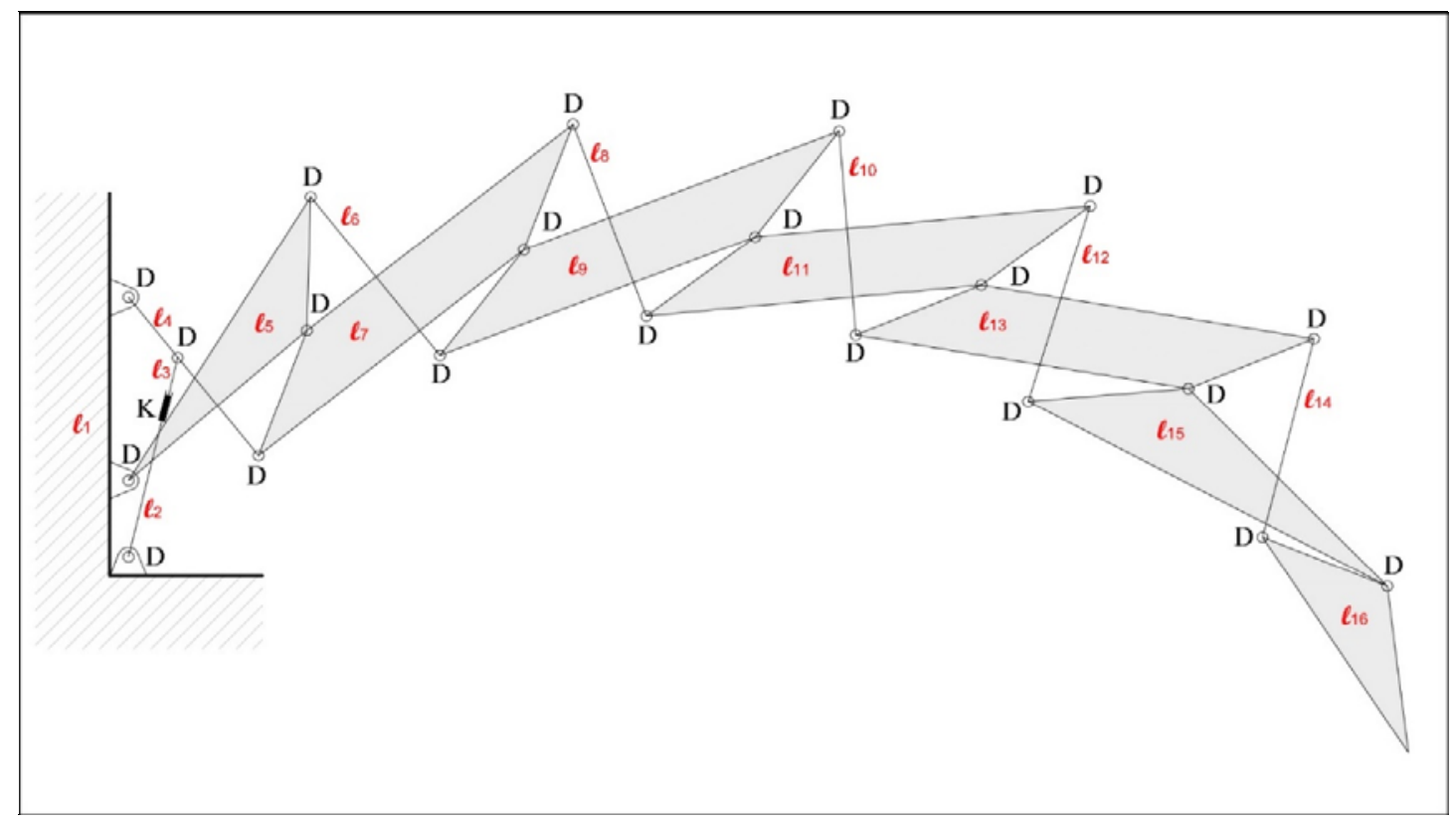

Şekil 9. Altı antiparalelkenar devreden oluşan tek serbestlikli mekanizma (One degree-of-freedom mechanism made of six antiparallel units) 


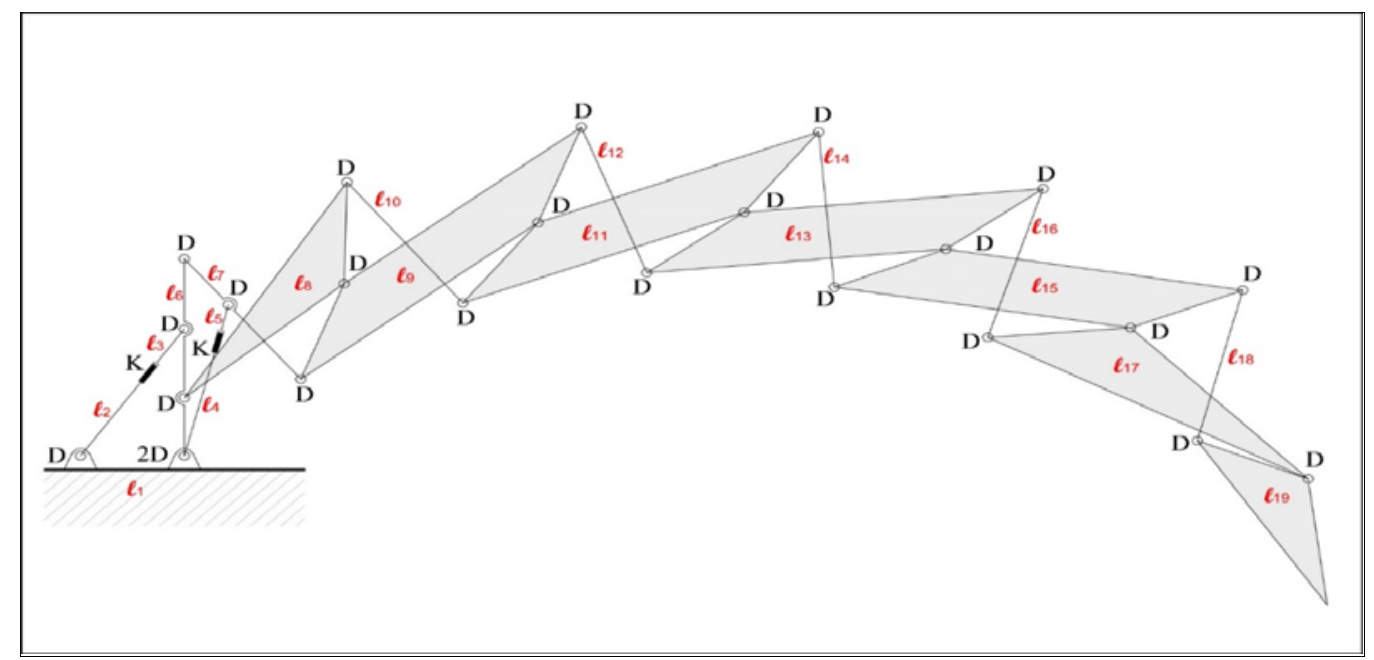

Şekil 10. Çift serbestlikli mekanizma (Two degrees-of-freedom mechanism)

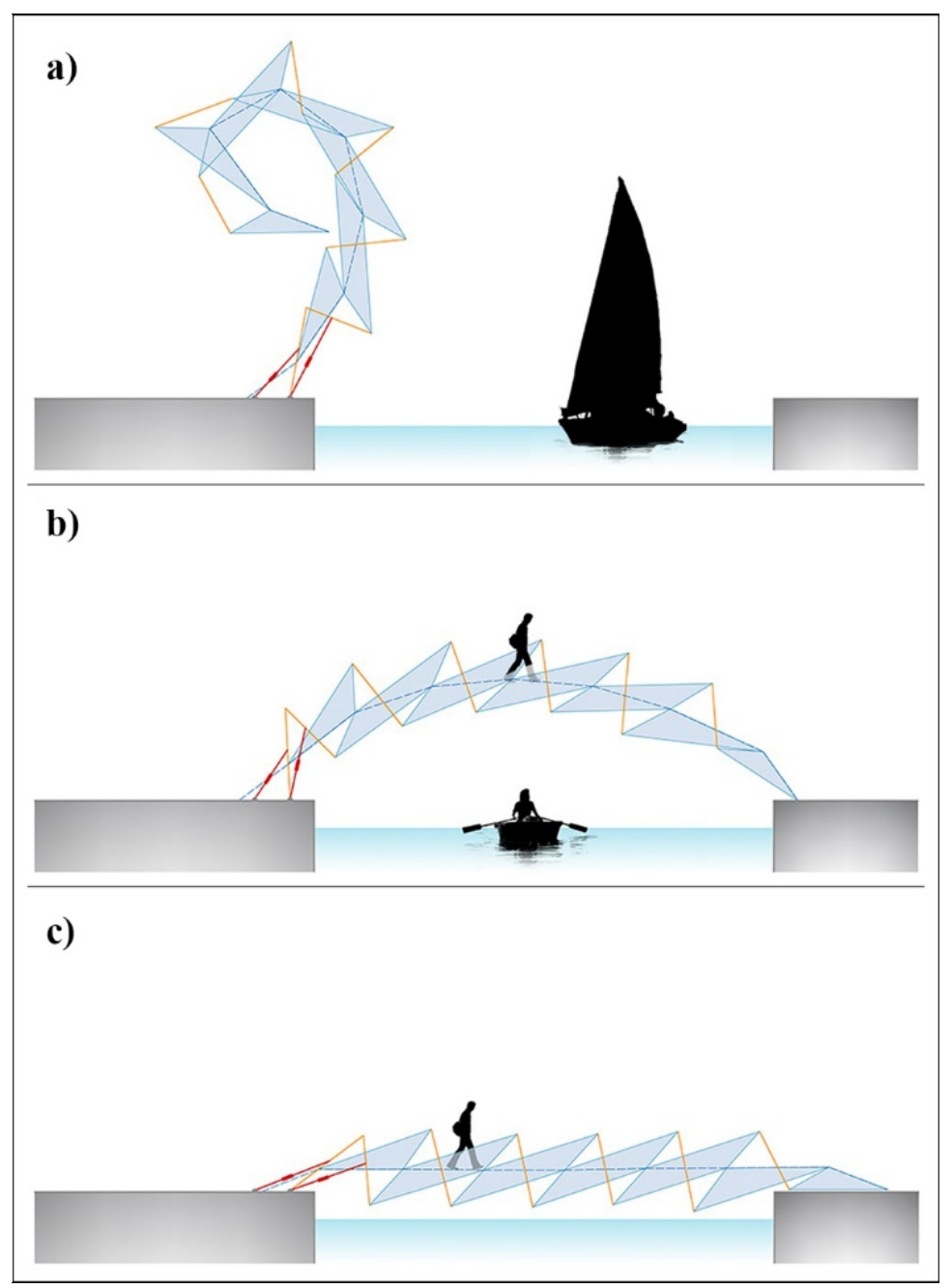

Şekil 11. Çift serbestlikli strüktürel mekanizmanın alternatif formları a) Yüksek deniz aracı geçişi için tek yakada toplanma b) Hem alçak deniz taşıtları hem de yaya geçişi sağlayan kemer form c) Deniz trafiğine izin vermeyen fakat yaya geçişini kolaylaştıran tam yatay form

(Form variations of the two degrees-of-freedom structural mechanism a) Bending towards one bank to let tall marine vehicles pass b) Arch form granting passage to both pedestrians and mid-height marine vehicles c) Horizontal form for easy pedestrian crossing, which blocks marine vehicles) 


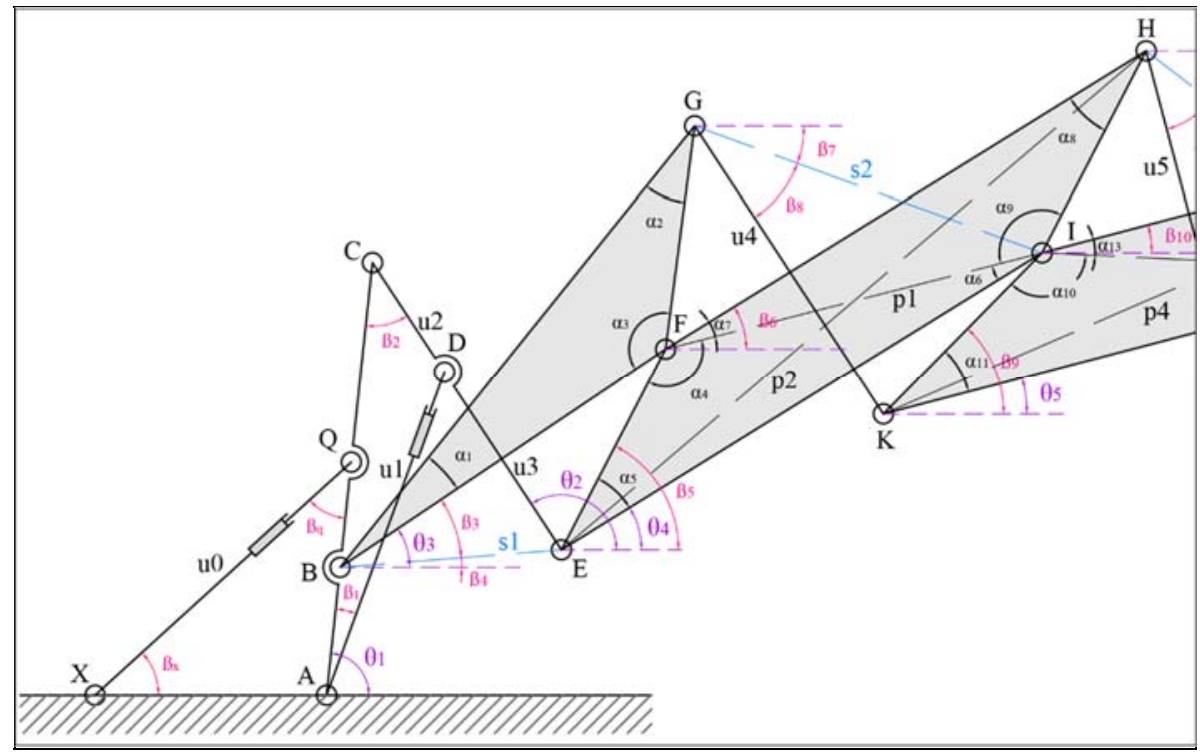

Şekil 12. Çift serbestlikli köprünün pozisyon analizi (Position analysis of the two degrees-of-freedom bridge)

$$
\mathrm{X}_{\mathrm{x}}=\mathrm{A}_{\mathrm{x}}-|\mathrm{AX}|, \mathrm{X}_{\mathrm{y}}=\mathrm{A}_{\mathrm{y}}=0 \text {. }
$$

Daha sonra $\beta_{\mathrm{x}}$ (Eş. 20) ve $\beta_{\mathrm{q}}$ (Eş. 21) iç açıları belirlenerek $\theta_{1}$ açısına (Eş. 22) ulaşılmalıdır:

$$
\begin{aligned}
& \beta_{\mathrm{x}}=\mathrm{A} \cos \left(\left(\mathrm{AX}^{2}+\mathrm{u}_{0}^{2}-\mathrm{AQ}^{2}\right) /\left(2 \times \mathrm{AX} \times \mathrm{u}_{0}\right)\right) \\
& \beta_{\mathrm{q}}=\mathrm{A} \cos \left(\left(\mathrm{AQ}^{2}+\mathrm{u}_{0}^{2}-\mathrm{AX} \mathrm{X}^{2}\right) /\left(2 \times \mathrm{AQ} \times \mathrm{u}_{0}\right)\right) \\
& \theta_{1}=\beta_{\mathrm{x}}+\beta_{\mathrm{q}}
\end{aligned}
$$

$\theta_{1}$ açısı kullanılarak Q noktasının koordinatları (Eş. 23) bulunabilir.

$$
\mathrm{Q}_{\mathrm{x}}=\mathrm{A}_{\mathrm{x}}+|\mathrm{AQ}| \times \cos \left(\theta_{1}\right), \mathrm{Q}_{\mathrm{y}}=\mathrm{A}_{\mathrm{y}}+|\mathrm{AQ}| \times \sin \left(\theta_{1}\right)
$$

B (Eş. 24) ve C (Eş. 25) noktaları da Q noktası ile aynı çizgi üzerinde bulunduğundan bu noktaların koordinatları da yine $\theta_{1}$ açısı kullanılarak saptanabilir:

$$
\begin{aligned}
& B_{x}=A_{x}+|A B| \times \cos \left(\theta_{1}\right), B_{y}=A_{y}+|A B| \times \sin \left(\theta_{1}\right) \\
& C_{x}=A_{x}+|A C| \times \cos \left(\theta_{1}\right), C_{y}=A_{y}+|A C| \times \sin \left(\theta_{1}\right)
\end{aligned}
$$

D noktasını (Eş. 27) bulmak için öncelikle $\beta_{1}$ iç açısı (Eş. 26) belirlenmelidir:

$$
\begin{aligned}
& \beta_{1}=A \cos \left(\left(\mathrm{AC}^{2}+\mathrm{u}_{1}^{2}-\mathrm{u}_{2}^{2}\right) /\left(2 \times A C \times \mathrm{u}_{1}\right)\right) \\
& \mathrm{D}_{\mathrm{x}}=\mathrm{A}_{\mathrm{x}}+\left(\mathrm{u}_{1} \times \cos \left(\theta_{1}-\beta_{1}\right)\right), \mathrm{D}_{\mathrm{y}}=\mathrm{A}_{\mathrm{y}}+\left(\mathrm{u}_{1} \times \sin \left(\theta_{1}-\beta_{1}\right)\right)
\end{aligned}
$$

E noktasını bulmak için ise öncelikle $\beta_{2}$ iç açısı (Eş. 28) ve $\theta_{2}$ açısı (Eş. 29) bulunmalıdır:

$$
\beta_{2}=\mathrm{Acos}\left(\left(\mathrm{AC}^{2}+\mathrm{u}_{2}^{2}-\mathrm{u}_{1}^{2}\right) /\left(2 \times \mathrm{AC} \times \mathrm{u}_{2}\right)\right)
$$

$\theta_{2}=\beta_{2}+\theta_{1}$

Ardından E noktası şu şekilde (Eş. 30) bulunabilir;

$E_{x}=C_{x}-\left(\left(u_{2}+u_{3}\right) \times \cos \left(\theta_{2}\right)\right), E_{y}=C_{y}-\left(\left(u_{2}+u_{3}\right) \times \sin \left(\theta_{2}\right)\right)$

Daha sonra mekanizmanın parçası olmayan ancak trigonometrik yöntemde üçgen oluşturmak için kullandığımız yardımcı $\mathrm{s}_{1}$ kenarı (Eş. 31 ) bulunarak $\beta_{2}$ (Eş. 32) ve $\beta_{2}$ (Eş. 33) açıları belirlenmelidir.

$s_{1}=\sqrt{\begin{array}{c}(|A C|-|A B|)^{2}+\left(u_{2}+u_{3}\right)^{2}-2 \times \\ (|A C|-|A B|) \times\left(u_{2}+u_{3}\right) \times \cos \left(\beta_{2}\right)\end{array}}$

$\beta_{3}=\mathrm{A} \cos \left(\left(\mathrm{BF}^{2}+\mathrm{s}_{1}{ }^{2}-\mathrm{EF}^{2}\right) /\left(2 \times \mathrm{BF} \times \mathrm{s}_{1}\right)\right)$

$\beta_{4}=\tan ^{-1}\left(\left(\mathrm{E}_{\mathrm{x}}-\mathrm{B}_{\mathrm{x}}\right) /\left(\mathrm{E}_{\mathrm{y}}-\mathrm{B}_{\mathrm{y}}\right)\right)$

$\theta_{3}$ açısı (Eş. 34) tespit edildikten sonra F noktası (Eş. 35) hesaplanabilir:

$\theta_{3}=\beta_{3}+\theta_{4}$

$\mathrm{F}_{\mathrm{x}}=\mathrm{B}_{\mathrm{x}}+\left(\mathrm{BF} \times \cos \left(\theta_{3}\right)\right), \mathrm{F}_{\mathrm{y}}=\mathrm{B}_{\mathrm{y}}+\left(\mathrm{BF} \times \sin \left(\theta_{3}\right)\right)$

G noktasını (Eş. 37) saptayabilmek için önce BFG üçgenin iç açısı olan $\alpha_{1}$ (Eş. 36) bulunmalıdır. BFG üçgenin diğer iç açıları da $\alpha_{1}$ açısını hesapladığımı yöntem ile bulunabilmektedir.

$\alpha_{1}=\mathrm{A} \cos \left(\left(\mathrm{BG}^{2}+\mathrm{BF}^{2}-\mathrm{GF}^{2}\right) /(2 \times \mathrm{BG} \times \mathrm{BF})\right)$

$\mathrm{G}_{\mathrm{x}}=\mathrm{B}_{\mathrm{x}}+\left(\mathrm{BG} \times \cos \left(\theta_{3}+\alpha_{1}\right)\right), \mathrm{G}_{\mathrm{y}}=\mathrm{B}_{\mathrm{y}}+\left(\mathrm{BG} \times \sin \left(\theta_{3}+\alpha_{1}\right)\right)$

Daha sonra H noktasını bulabilmemiz için kullanacağımız EFHI dörtgeninin iç açısı olan $\alpha_{4}$ (Eş. 38) ve $\alpha_{7}$ (Eş. 39) ile 
$\beta_{5}$ açısı (Eş. 40) bulunmalıdır. EFHI dörtgeninin diğer iç açıları olan $\alpha_{5}, \alpha_{6}, \alpha_{8}, \alpha_{9}$ açıları da benzer yöntemle bulunabilmektedir.

$$
\begin{aligned}
& \alpha_{4}=\operatorname{Acos}\left(\left(\mathrm{p}_{1}{ }^{2}+\mathrm{EF}^{2}-\mathrm{EI}^{2}\right) /\left(2 \times \mathrm{p}_{1} \times \mathrm{EF}\right)\right) \\
& \alpha_{7}=\operatorname{Acos}\left(\left(\mathrm{p}_{1}{ }^{2}+\mathrm{FH}^{2}-\mathrm{HI}^{2}\right) /\left(2 \times \mathrm{p}_{1} \times \mathrm{FH}\right)\right) \\
& \beta_{5}=\tan ^{-1}\left(\left(\mathrm{~F}_{\mathrm{x}}-\mathrm{E}_{\mathrm{x}}\right) /\left(\mathrm{F}_{\mathrm{y}}-\mathrm{E}_{\mathrm{y}}\right)\right)
\end{aligned}
$$

$\mathrm{B}_{6}$ açısı (Eş. 41) da bulunarak H noktasının koordinatları (Eş. 42) tespit edilebilir.

$\beta_{6}=\alpha_{4}+\alpha_{7}+\beta_{5}-\pi$

$$
\mathrm{H}_{\mathrm{x}}=\mathrm{F}_{\mathrm{x}}+\left(\mathrm{FH} \times \cos \left(\beta_{6}\right)\right), \mathrm{H}_{\mathrm{y}}=\mathrm{F}_{\mathrm{y}}+\left(\mathrm{FH} \times \sin \left(\beta_{6}\right)\right)
$$

I noktasını (Eş. 45) bulabilmek için EFHI dörtgeninin iç açısı olan $\alpha_{5}$ açısı (Eş. 43) ve $\theta_{3}$ açısı (Eş. 44) belirlenmelidir.

$$
\begin{aligned}
& \alpha_{5}=A \cos \left(\left(\mathrm{EF}^{2}+\mathrm{EI}^{2}-\mathrm{p}_{1}{ }^{2}\right) /(2 \times \mathrm{EF} \times \mathrm{EI})\right) \\
& \theta_{4}=\beta_{5}+\alpha_{5} \\
& \mathrm{I}_{\mathrm{x}}=\mathrm{E}_{\mathrm{x}}+\left(\mathrm{EI} \times \cos \left(\theta_{4}\right)\right), \mathrm{I}_{\mathrm{y}}=\mathrm{E}_{\mathrm{y}}+\mathrm{EI} \times \sin \theta_{4}
\end{aligned}
$$

Bir kez daha trigonometrik hesaba yardımcı olacak $\mathrm{s}_{2}$ kenar1 (Eş. 46) bulunarak $\beta_{7}$ (Eş. 47) ve $\beta_{8}$ (Eş. 48) iç açıları belirlenmelidir:

$$
\begin{aligned}
& \mathrm{s}_{2}=\sqrt{\left(\mathrm{I}_{\mathrm{x}}-\mathrm{G}_{\mathrm{x}}\right)^{2}+\left(\mathrm{I}_{\mathrm{Y}}+\mathrm{G}_{\mathrm{y}}\right)^{2}} \\
& \beta_{7}=\tan ^{-1}\left(\left(\mathrm{I}_{\mathrm{x}}-\mathrm{G}_{\mathrm{x}}\right) /\left(\mathrm{I}_{\mathrm{y}}-\mathrm{G}_{\mathrm{y}}\right)\right) \\
& \beta_{8}=\mathrm{A} \cos \left(\left(\mathrm{u}_{4}{ }^{2}+\mathrm{S}_{2}{ }^{2}-\mathrm{KI}^{2}\right) /\left(2 \times \mathrm{u}_{4} \times \mathrm{s}_{2}\right)\right)
\end{aligned}
$$

Gerekli olan tüm açılar bulunmuş olduğu için K noktası (Eş. 49) artık hesaplanabilir:

$$
\mathrm{K}_{\mathrm{x}}=\mathrm{G}_{\mathrm{x}}+\left(\mathrm{u}_{4} \times \cos \left(\beta_{7}-\beta_{8}\right)\right), \mathrm{K}_{\mathrm{y}}=\mathrm{G}_{\mathrm{y}}+\left(\mathrm{u}_{4} \times \sin \left(\beta_{7}-\beta_{8}\right)\right)
$$

Pozisyon analizinde ikinci dörtgen uzuv olan IJKN dörtgeninin iki noktası I ve K noktaları bu aşamaya kadar hâlihazırda tespit edilmiştir. Yukarıdaki yöntem takip edilerek sistemin geri kalanı için de pozisyonlar formüle edilerek hesaplanabilir. Mekanizmanın tasarımında çubuk elemanların boyutlarını belirlemek için kullanım ve koşulların ortaya çıkardığı bazı kıstaslar belirlenmiştir. Bunların ilki geçilmesi amaçlanan mesafedir. Bu çalışma kapsamındaki hesaplamalar Rolling Bridge'in geçtiği mesafe olan $12 \mathrm{~m}$ olarak belirlenmiştir. İkinci tasarım kıstası köprünün düz pozisyonda güvertenin monte edildiği mafsalların düz formu alacak şekilde hizalanmasıdır. Son olarak ise, yayaların güvenliğini sağlayabilecek $90 \mathrm{~cm}$. korkuluk yüksekliğinin sağlanmasıdır. Yaptığımız çalışmada kenar boyları ve formüller Microsoft Excel ${ }^{\circledR}$ programında girilerek pozisyon analizi otomatize edilmiştir (Şekil 13, 14). Bu sistem ile çeşitli kenar uzunlukları sadece bir verinin değişmesi ile mümkün olmaktadır. Bu sayede yukarıda belirlenen kıstaslara uyan bir tasarım, paralekenar devrelerin kenar boyları ve piston boylarını değiştirilerek çıkan sonucun gözlenmesi ile manuel olarak gerçekleştirilmiştir.

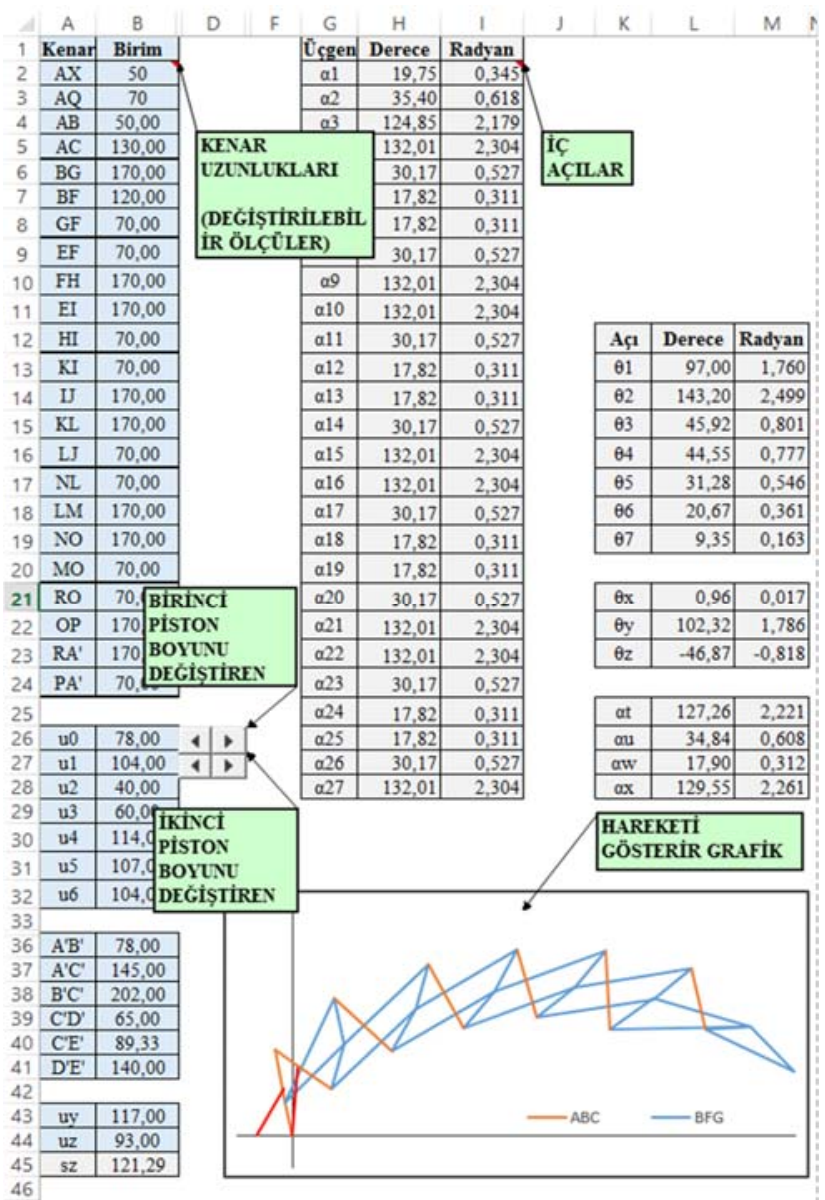

Şekil 13. Microsoft Excel ${ }^{\circledR}$ ortamında pozisyon analizi sayfa 1 (Position analysis in Microsoft Excel ${ }^{\circledR}$ page 1)

Şekil 13, 14'te yer alan tabloda mavi olan kutular değiştirilebilir kenar uzunluklarını belirtmektedir. $u_{0}$ ve $u_{1}$ kutucuklarının yanında yer alan oklar ile piston boyları ayarlanarak köprü formu değiştirilebilmektedir. Noktaların elde edilen konumları kullanılarak program içerisinde çizdirilen grafik ile de görselleştirme sağlanmıştır. Uygulanan parametrik yöntem neticesinde sistemin herhangi bir kenar boyu veya piston mesafesi değiştirilirse tüm pozisyon analizi gerçek zamanlı olarak güncellenmekte ve grafikte görüntülenmektedir. Köprünün tasarımında uzuvların formu kinematik gösterimden bağımsız olarak belirlenebilir. Şekil 8'deki ön çalışma prototipinde de olduğu gibi, mafsal yerlerini değiştirmeksizin, uzuvları stilize edebiliriz. Aşağıda Excel dosyasındaki mafsal mesafelerine uyarak 12 metre açıklık geçebilen bir köprünün stilize edilmiş bir bilgisayar modeli görülmektedir (Şekil 15). 


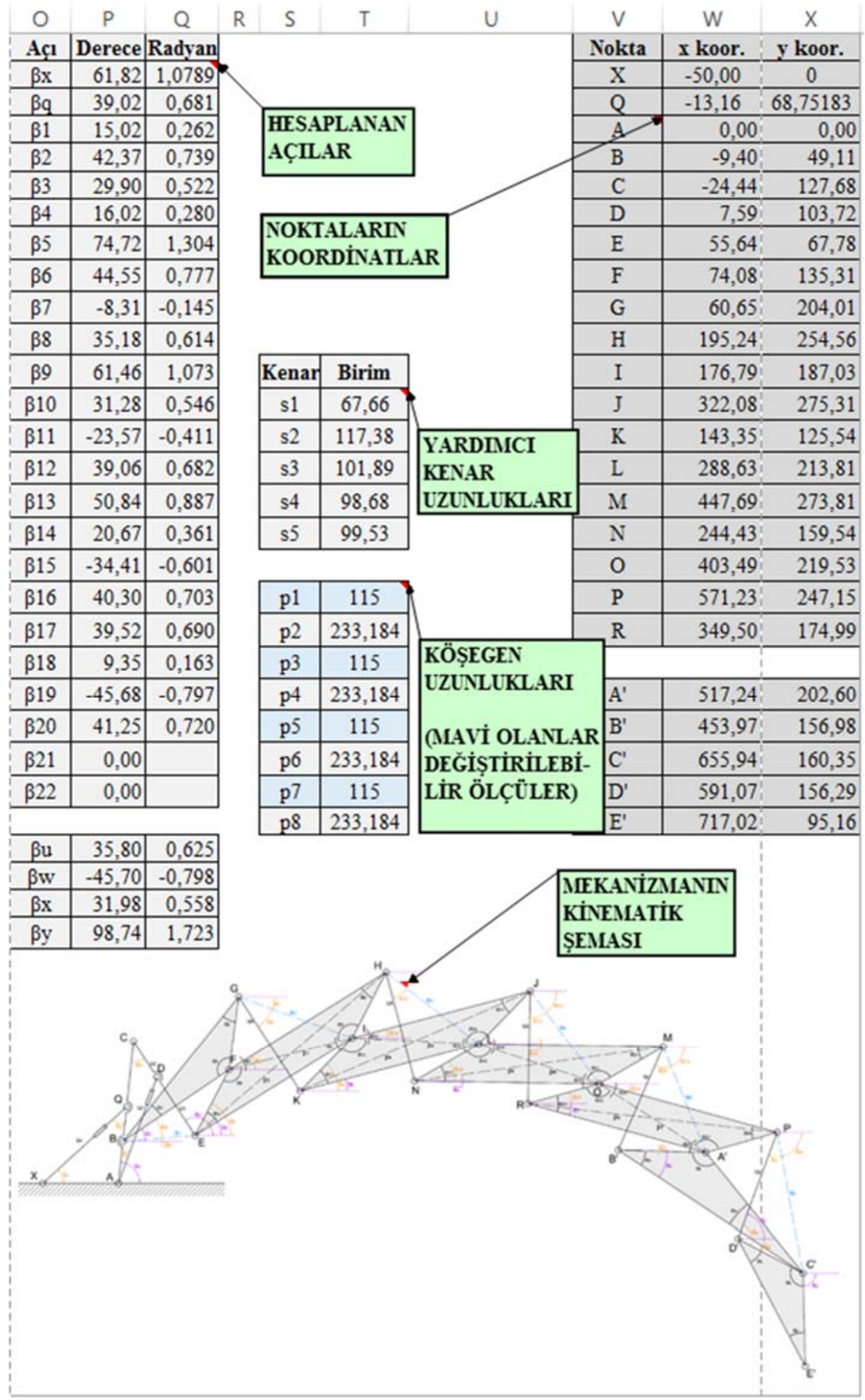

Şekil 14. Microsoft Excel ${ }^{\circledR}$ ortamında pozisyon analizi, sayfa 2 (Position analysis in Microsoft Excel®, page 2)

$\mathrm{Bu}$ tasarımda köprünün toplanmış halindeki formun bir akrebin kuyruğuna benzerliğinden esinlenilmiş ve tasarım 'Akrep Köprüsü' olarak adlandırılmıştır. Modelde sistemin güverte ve korkuluk birleşimleri de görülebilmektedir. Güverteyi oluşturan parçaların her biri iki uzvu birleştiren mafsala bir aks ile monte edilmektedir. Köprünün monte olduğu yakadaki ilk güverte parçası mafsallara değil sadece 1388 sonraki güverte parçasına monte edilmiştir. $\mathrm{Bu}$ şekilde zeminde içerinde kayarak köprünün pozisyon değişimi sırasında değişen mesafeye adapte olmaktadır. Aynı şekilde korkuluklar da uzuvların birleştiği üst sıradaki mafsallara monte edilmiştir. Uzuvlar arasındaki değişen mesafelere adapte olabilmesi için korkuluklar iki parçadan oluşan ve birbiri içine kayabilen teleskopik yapıdadır (Şekil 16). 


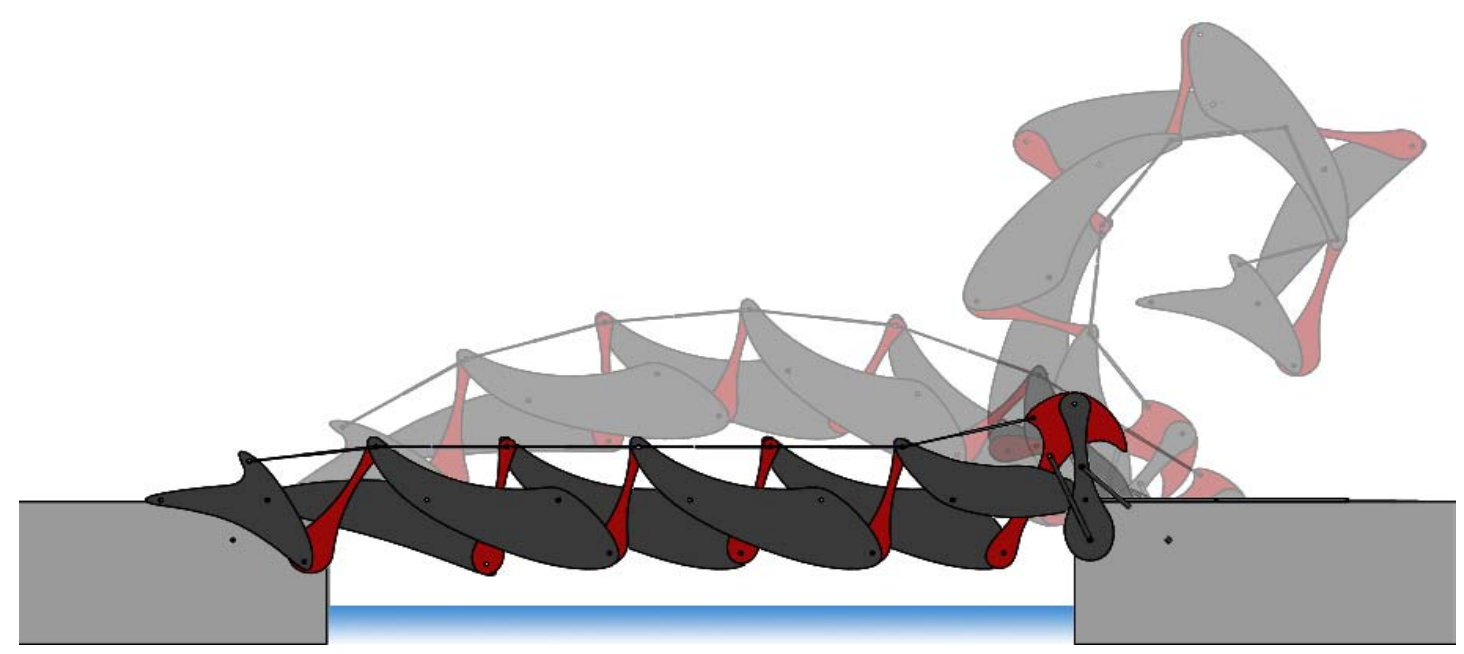

Şekil 15. Stilize edilmiş 'Akrep Köprü’ tasarımı (Stylized design of the 'Scorpion Bridge')

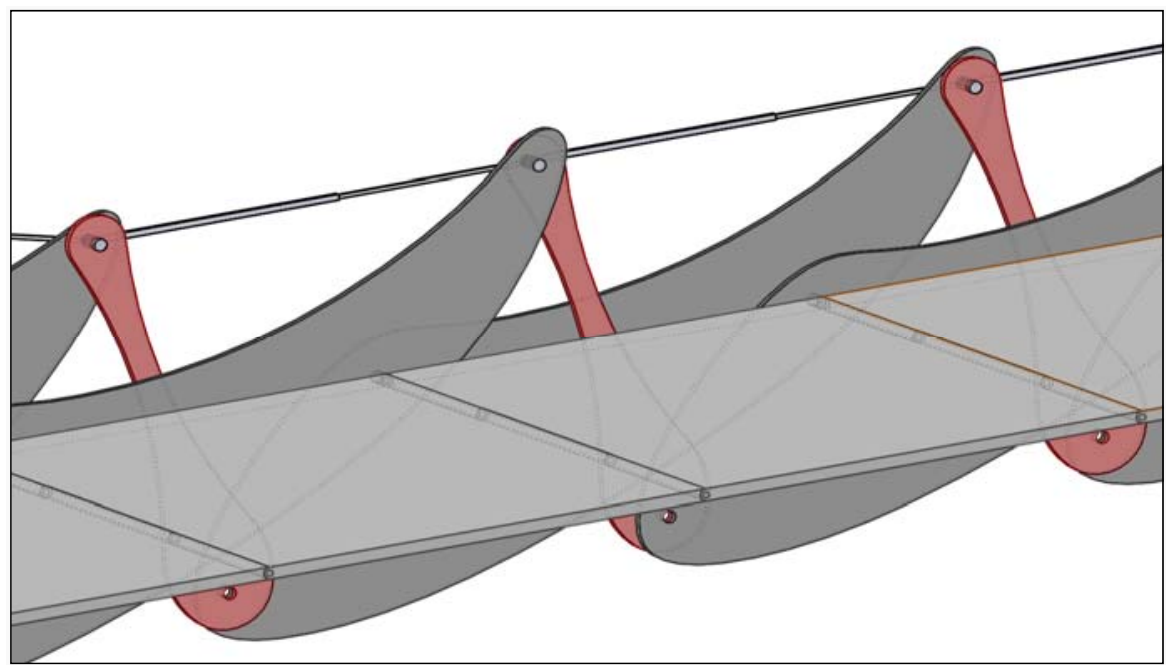

Şekil 16. Güverte ve korkuluk birleşim detayları (Deck and railing connection details)

Tablo 1. Köprülerin kullanım senaryolarının değerlendirmesi (Evaluation of usage scenarios of bridges)

\begin{tabular}{|c|c|c|c|}
\hline \multirow[b]{2}{*}{ Köprü adı } & \multicolumn{3}{|c|}{ Kullanım senaryoları } \\
\hline & $\begin{array}{l}\text { Köprü zeminin düz } \\
\text { formu ile yaya } \\
\text { geçişini mümkün } \\
\text { kılması }\end{array}$ & $\begin{array}{l}\text { Köprü zemininin kemer formu ile } \\
\text { yaya geçişine izin verirken } \\
\text { altından küçük deniz araçlarının } \\
\text { da geçişini mümkün kılması }\end{array}$ & $\begin{array}{l}\text { Köprünün tek yakada } \\
\text { toplanarak yüksek deniz } \\
\text { araçlarının geçişini } \\
\text { mümkün kılması }\end{array}$ \\
\hline $\begin{array}{l}\text { Hörn yaya } \\
\text { köprüsü }\end{array}$ & $X$ & & 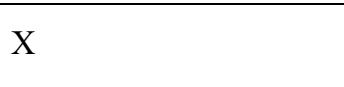 \\
\hline Duisburg iç & & & \\
\hline $\begin{array}{l}\text { körfez yaya } \\
\text { köprüsü }\end{array}$ & $\mathrm{X}$ & $X$ & \\
\hline $\begin{array}{l}\text { (Lederman vd.) } \\
\text { Aç1labilir köprü }\end{array}$ & & $\mathrm{X}$ & $\mathrm{X}$ \\
\hline $\begin{array}{l}\text { Hiroshima Üni. } \\
\text { acil durum } \\
\text { köprüsü }\end{array}$ & $\mathrm{X}$ & & $\mathrm{X}$ \\
\hline Rolling Bridge & $\mathrm{X}$ & & $X$ \\
\hline $\begin{array}{l}\text { Jet d'Eau yaya } \\
\text { köprüsü }\end{array}$ & $\mathrm{X}$ & $\mathrm{X}$ & \\
\hline Akrep Köprü & $\mathrm{X}$ & $\mathrm{X}$ & $X$ \\
\hline
\end{tabular}




\section{SONUÇLAR (CONCLUSIONS)}

$\mathrm{Bu}$ makalede öncelikle altı adet köprünün hareket ederek imkân verdikleri kullanım senaryoları incelenmiştir. Üç farklı kullanım senaryosu tespit edilmiştir. $\mathrm{Bu}$ senaryolar; hareketli köprünün zemini yere paralel düz forma dönüştürerek yayaların geçişini mümkün kılması, zemini kemer formuna dönüștürerek üstünden yayaların ve altından küçük deniz araçlarının geçmesini mümkün kılması veya bir yakada toplanarak yüksek deniz araçlarının geçişini mümkün kılmasıdır. İncelenen altı köprünün bu üç kullanım senaryosundan sadece ikisine cevap verebildikleri gözlemlenmiştir (Tablo 1). Bu köprüler hareket ederek sadece bir formdan ikinci bir forma dönüşebilmeleri için tasarlanmıştır. İncelenen köprüler arasında sadece rijit çubuk mekanizmaların kullanıldığı örnekler olduğu gibi kablo ve dişli mekanizmalarının da tasarıma dahil edildiği daha karmaşık mekanizmalar da kullanılmıştır. Kablo gibi esnek elemanların da kullanıldığı mekanizmalarda köprü ilk formdan ikinci forma dönüşürken kabloların gergin olmadığ1 anlarda hareket kontrol edilemez. Kablolar yeterince gerilinceye kadar bu durum devam eder. Sadece rijit çubuk elemanların kullanıldığ 1 köprü mekanizmalarında hareketin her anı kullanıcının kontrolündedir ve daha güvenlidir. Bu sebeple bu çalışmada sadece rijit çubuk elemanlar kullanılmıştır. Rijit çubuk elemanların kullanıldığı bir mekanizmayı iki farklı form arasında hareket ettirmek için tek serbestlik derecesi yeterlidir. Detaylı analizinin sunulduğu 12 metre açıklık geçen Heatherwick köprüsünde yedi serbestlik derecesi vardır. Aynı açıklık için benzeri iki farklı formu alabilen tek serbestlik dereceli çok devreli bir mekanizma önce antiparalelkenar birimlerin birleştirilmesinden oluşturuldu. Her devre arasında iki ortak uzuv kullanılarak serbestlik derecesi artmadan çok devreli bir yapı tasarland1. Önerilen mekanizma konkav ile konveks formlar arasında geçiş yapabilmektedir. Tek serbestlik derecesi ile tasarlanan köprü mekanizması yine zeminini kemer formuna dönüştürerek ve bir yakada toplanarak iki kullanım senaryosuna izin vermekteydi. Üçüncü kullanım senaryosuna imkân vermek için mekanizma iki serbestlik dereceli olacak şekilde geliştirildi. Böylelikle köprü zemini düz forma da dönüşerek üçüncü kullanım senaryosuna imkân verebilmiştir. Yapılan prototip ve simülasyonlarla ise inşa edilebilirlik test edildi. Pozisyon analizi için hazırlanan tabloya manuel olarak belirlenen kıstaslara göre veri girerek önerilen köprü mekanizmasının her çubuk boyuna karar verilmiştir. Önerilen mekanizma yeni antiparalelkenar birimlerin eklenmesi ile daha geniş açıklıklı köprülerde de uygulanabilir. Uygulamaya dönük detaylar dikkatli çalışılmalıdır. Hareketli sistemlerin tasarımında hareketin her anının gözlemlenmesi gerekir çünkü birbirine dokunmayan iki parça hareketin bir anında birbirine dokunup sistemi kilitleyebilmektedir. Bu sebeple tasarım Solidworks gibi hareketi gözlemlememize olanak veren programlarla yapılmalıdır. Ayrıca önerilen iki boyutlu mekanizma birbirine paralel değil de birbirine dik monte edilerek üç boyutluluk araştırılabilir. Hatta iki boyutlu birimleri tamamen kenara koyup üç boyutlu birimler geliştirerek bunların birleştirilmesiyle üç boyutlu çok devreli hareketli eğrilikli yüzeyler de çalışılabilir. Çift eğrilikli yüzeylerin nasıl form değiştirebileceği gelecekteki bir araştırma konusu olabilir.

\section{TEŞEKKÜR (ACKNOWLEDGEMENT)}

$\mathrm{Bu}$ proje Avrupa Birliği Horizon 2020 araştırma ve geliştirme programından Marie Skłodowska-Curie hibe antlaşması No 689983 uyarınca finanse edilmiştir.

\section{KAYNAKLAR (REFERENCES)}

1. Fränkel W., Der Brückenbau-Bewegliche Brücken, Handbuch der Ingenieurwissenschaften, Verlag Wilhelm Engelmann, Leipzig (in German), 1882.

2. Hardesty E.R., Christie R.W., Fischer H.W., Fifty-year History of Movable Bridge Construction-Part I, J. Constr. Div., 101 (3), 511-527, 1975.

3. Hardesty E.R., Christie R.W., Fischer H.W., Fifty-year History of Movable Bridge Construction-Part II, J. Constr. Div., 101 (3), 529543, 1975.

4. Wengenroth R.H., Hardesty E.R., Mix H.A., Fifty-year History Of Movable Bridge Construction-Part III, J. Constr. Div., 101 (3), 545-557, 1975.

5. Waddell J.A.L., The Halstead Street lift bridge, Trans. Am. Soc. Civ. Eng., 33 (1), 1-60, 1895.

6. Greene W.K., McKeen E.E., Erecting the Marine Parkway Bridge, Eng. News-Rec., 371-374, 1938.

7. Quade M.N., Special design features of the Yorktown Bridge, Trans. Am. Soc. Civ. Eng., 119 (1), 109-123, 1954.

8. Abrahams M.J., Bridge Engineering Handbook, CRC, New York, Chap. 21., 2000.

9. Koglin T.L., Movable Bridge Engineering, Wiley, Hoboken, N.J., 2003.

10. Knippers J., Schlaich J., Folding Mechanism of the Kiel Hörn Footbridge, Germany, Structural Engineering International, 10.1, 50-53, 2000.

11. Butz, C., Magalhaes, F., Cunha, A., Caetano, E., Goldack, A., Experimental Characterization of the Dynamic Behaviour of Lively Footbridges, 2nd International Conference on Footbridge, Venice.

12. Lederman G., You Z., Glišić B., A Novel Deployable Tied Arch Bridge, Eng. Struct., 70, 1-10, 2014.

13. Ario I., Nakazawa M., Tanaka Y., Tanikura I., Ono S., Development of a Prototype Deployable Bridge Based on Origami Skill, Automat. Constr., 32, 104-111, 2013.

14. Packman R., The Rolling Bridge, Paddington Basin, Struct. Eng., 83 (2), 2005.

15. Brown J.L., Rolling London Footbridge Surprises Spectators, Civ. Eng., 2005.

16. Reina P., This London Bridge Doesn't Fall Down - It Does a Backbend, Archit. Rec., 192 (12), 230, 2004.

17. Maden F., Akgün Y., Korkmaz K.,A Review of Planar Scissor Structural Mechanisms Geometric Principles and Design Methods, Architectural Science Review, 2011.

18. Cai J., Zhou Y., Zhu Y., Feng J., Xu Y., Zhang J., Geometry and Mechanical Behaviour of Radially Retractable Roof Structures during the Movement 
Process, International Journal of Steel Structures, 16 (3), 755-764, 2016.

19. Bouleau E., Guscetti G., Scissor Mechanisms for Transformable Structures with Curved Shape, Advances in Architectural Geometry 2016, vdf Hochschulverlag AG, 2016.

20. Hoberman, C., U.S. Patent No. 4,942,700. Washington, DC: U.S. Patent and Trademark Office, 1990.

21. Bakbak D., Özakça M., Göğüş M.T., Development of Design Methodologies for Deployable Fabric Structures in Civil Engineering, Journal of the Faculty of Engineering \& Architecture of Gazi University, 31 (1), 73-86, 2016.

22. Jang G., Lee C., Lee H., Choi Y., Robotic Index Finger Prosthesis Using Stackable Double 4-BAR Mechanisms, Mechatronics, 23 (3), 318-325, 2013.
23. Li G., Zhang C., Zhang W., Sun Z., Chen Q., Coupled and Self-Adaptive Under-Actuated Finger with a Novel S-Coupled and Secondly Self-Adaptive Mechanism, J. Mech. Robot., 6 (4), 041010, 2014.

24. Phillips J., Freedom in Machinery, Cambridge University Press, 2006.

25. Kutzbach K., Mechanische Leitungsverzweigung, ihre Gesetze und Anwendungen, Maschinenbau, Betrieb, 8, 710-716, 1929.

26. Freudenstein F., Alizade R., On The Degree-OfFreedom of Mechanisms with Variable General Constraint, In: Fourth World Congress on the Theory of Machines and Mechanisms Newcastle upon Tyne, 52$56,1975$.

27. Söylemez E., Makina Teorisi - 1: Mekanizma Tekniği, Birsen Publishing, 3. Edition, 2010. 
